Acta Cryst. (2002). A58 (Supplement), C18

\section{ORGANOPLATINUM SUPERMOLECULES FOR GAS-TRIGGERED CRYSTALLINE SWITCHES}

G. Van Koten M. Albrecht A.L. Spek M. Lutz

Utrecht University Department of Metal-Mediated Synthesis Padualaan 8 Utrecht 3584 Ch Netherlands

Our approach to crystal engineering (1) involves square-planar platinum (II) complexes containing terdentate coordinating pincer-type ligands. These complexes reversibly absorb gaseous $\mathrm{SO}_{2}$ in the solid state by $\mathrm{Pt}-\mathrm{S}$ bond formation (2). When the starting material is crystalline, exposure to $\mathrm{SO}_{2}$ gas leads to quantitative adduct formation with the unique feature that the product is also crystalline, although the crystal structures of the adduct and the $\mathrm{SO}_{2}$ free complex are significantly different from each other. Remarkably, the release of $\mathrm{SO}_{2}$ gas does modify but not destroy the crystalline ordering in the arylplatinum assemblies. These crystalline transformations include repetitive expansion and reduction of the crystal lattice without detectable loss of crystallinity of the material (3). The potential of this class of supermolecules as crystalline switches with 'on' and 'off' positions which are a direct response on the gaseous environment will be discussed.

References

(1) a) Desiraju, G. R. (ed.) The Crystal as a Supramolecular Entity, Wiley: Chichester, 1996; b) Braga, D.; Grepioni, F.; Desiraju, G. R. Chem. Rev. 1998 98, 1375.

(2) A) Albrecht, M.; Van Koten G. Adv. Mater. 1999, 11, 171; B) Albrecht M.; Gossage, R. A.; Lutz, M.; Spek, A. L.; Van Koten, G. Chem. Eur. J. 2000, 6, 1431. (3) Albrecht, M.; Lutz, M.; Spek, A. L.; Van Koten, G. Nature. 2000, 406, 970-974.

Keywords: ORGANOMETALLIC SWITCHES SO2-ABSORPTION

Acta Cryst. (2002). A58 (Supplement), C18

\section{THE COORDINATION AND CATALYTIC PROPERTIES OF THE 1,1'-DIPHENYL-3,3',4,4'-TETRAMETHYL-2,2'-BIPHOSPHOLE} \section{J.C. Daran}

CNRS Laboratoire De Chimie De Coordination 205, Route De Narbonne Toulouse 31077

Chiral diphosphine ligands, in particular those belonging to $C 2$-symmetry class, have been proved to be powerful auxiliaries in catalytic asymmetric processes. Since 1994, we are interested in the possibilities offered by the 1,1'diphenyl-3,3',4,4'-tetramethyl-2,2'-biphosphole 1 (BIPHOS), first synthesized by F. Mathey et al. ${ }^{1}$. This diphosphine which combines the axial chirality generated by the biphosphole framework with the central chiralities of the phosphorus atoms is stereolabile in solution and six stereoisomers are in fast equilibrium at room temperature ${ }^{2}$. Among these three diastereoisomers, one has a favorable configuration for chelating metals (see figures).

The synthesis and structures of numerous transition metal complexes are reported ${ }^{3}$ Their X-ray analysis proved that in each complex the 2,2'-biphosphole ligand have the expected configuration. The efficiency of some complexes as catalyst was demonstrated in racemic version. Then, we have investigated the preparation of enantiomerically pure complexes from enantiomerically pure BIPHOS ligand in order to explore the potential of these complexes in asymmetric catalysis ${ }^{4}$.

References

1- F. Mercier; S. Holand; F. Mathey J. Organomet. Chem. 1986, 316, 271.

2- O. Tissot; M. Gouygou; J-C. Daran, G.G.A. Balavoine J. Chem. Soc., Chem. Comm. 1996, 2287.

3- O. Tissot, J. Hydrio, M. Gouygou, F. Dallemer, J-C. Daran, G. G. A. Balavoine, Tetrahedron, 2000, 56, 85.

4- a) O. Tissot, M. Gouygou, F. Dallemer, J-C. Daran, G. G. A. Balavoine, Angew. Chem. Int. Ed. Engl. 2001, 40, 1076; b) O. Tissot, M. Gouygou, F. Dallemer, J-C. Daran, G. G. A. Balavoine, Eur. J. Inorg. Chem. 2001, 23852389.
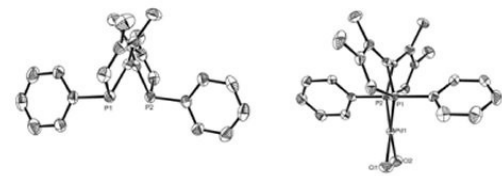

Acta Cryst. (2002). A58 (Supplement), C18

\section{DNA-PLANAR COPPER COMPLEXES INTERACTION, $\pi-\pi$}

STACKING VS H BOND

R. Moreno-Esparza ${ }^{1}$ S. Escalante-Tovar ${ }^{1}$ L. Ruiz-Ramirez ${ }^{1}$

Facultad De Qul'imica UNAM (MEXICO) Inorganic Chemistry Av. Universidad 3000, Facultad De Qul'imica, Bldg. B Ciudad Universitaria, Coyoacl'an M।'EXICO D.F. 04510 MEXICO

Biological structures are the most important examples of supramolecular chemistry. Undeniably, interactions such as $\pi-\pi$ stacking, hydrogen bonds and host-guest play an important role in the formation of supramolecules. While $\pi$ stacking is an old argument for conformational stability, progress in understanding its molecular origins has been recent. Considering this, phenathroline is an excellent rigid ligand liable to have intermolecular interactions such as hydrogen bonding and $\pi-\pi$ stacking with other molecules. A series of mixed chelate copper (II) complexes of general formulae $[\mathrm{Cu}(\mathrm{N}-$ $\mathrm{N})(\mathrm{O}-\mathrm{O})] \mathrm{NO}_{3}$ or $[\mathrm{Cu}(\mathrm{N}-\mathrm{N})(\mathrm{O}-\mathrm{N})] \mathrm{NO}_{3}$ have been registered as anticancer agents under the name of CASIOPEINAS [Were: N-N=Substituted 1,10phenanthrolines or 2,2'-Bipyridines, $\mathrm{N}-\mathrm{O}=$ aminoacidates, $\mathrm{O}$ $\mathrm{O}=$ acetylacetonate or salicilaldehidate]. These compounds have shown cytotoxic and antineoplastic activity in vitro and in vivo, and also show SOD like activity. They also shown mutagenic activity in Drosophila melanogaster and induce apoptosis, which may indicate direct interaction between DNA and the complexes. We also found, that many crystal structures with phenanthroline or bipyridine show antiparallel ring-stacking with distances among planes less than $3.5 \AA$. Additionally our study of the interaction between DNA and these complexes, show they are able to associate with the DNA molecule. The association constant value, correspond to an intercalation process. This led us study the host-guest interaction of a small DNA chain with several of these complexes using a docking program to find the site were these complexes can accommodate in the DNA structure, and compare the energetics of the $\pi-\pi$ stacking interaction with the H-bond on the selected moiety.

Keywords: STACKING, $\pi-\pi$ INTERACTIONS, METAL COMPLEXES

Acta Cryst. (2002). A58 (Supplement), C18

WATER SOLUBLE CATALYSIS - LIGANDS AND COMPLEXES A. Benyei

University of Debrecen, Department of Chemistry, Laboratory for X-ray Diffraction H/4010 Debrecen POB 7 HUNGARY

Water-soluble complex catalyzed reactions have been gaining significant importance recently, because of the environmental friendly nature of the solvent (water) and interesting chemistry as well as selectivity of catalytic systems. Selected applications include carbonylation, hydroformylation, hydrogenation, hydrogen transfer reaction, hydrodehalogenation, carbon dioxide reduction, biological membrane hydrogenation etc. In some cases industrial scale processes are working on the basis of this chemistry. The main method to make a platinum group metal complex catalyzed homogeneous system aqueous is to apply water-soluble ligands i.e. sulfonated phosphanes. However, review of CCDC database shows that only very limited number of such structures are available because of the difficulties to grow single crystals. Our results show that guanidine and melamine form readily hydrogen bonds with sulfonated phosphanes1 as well as with their metal complexes and this crystallization trick made it possible to determine approx. a dozen of new structures of this class. These structures are important not only from the catalytic point of view but they show very extensive hydrogen bond network and interesting supramolecular assemblies.

Acknowledgement: This work was supported by the Hungarian Research Fund and Ministry of Education, Hungary.

References

1 A. Katho, A. Benyei, F. Joo and M. Sagi, Aplied Synthesis and Catalysis, in press

Keywords: PHOSPHANES CATALYSIS HYDROGEN BOND 